Article

\title{
Effect of Cross-Frames on Load Distribution of Steel Bridges with Fractured Girder
}

\author{
Mohammad Abedin *(i) and Armin B. Mehrabi (1) \\ Department of Civil and Environmental Engineering, Florida International University, Miami, FL 33174, USA; \\ amehrabi@fiu.edu \\ * Correspondence: mabed005@fiu.edu
}

Received: 4 February 2020; Accepted: 1 April 2020; Published: 1 April 2020

\begin{abstract}
In steel girder bridges, fracture of one girder may occur without noticeable bridge profile changes. It is critical to ensure that the bridge will have adequate capacity to prevent collapse until the next cycle of inspection discovers the damage. It is realized that once one of the bridge girders is fractured, vertical loads need to be distributed through an alternative path to the intact girder(s). In this case, cross-frames can play an important role in transferring the loads and preventing from sudden collapse. This paper investigates the impact of cross-frames on load distribution after a fracture is occurred in one girder. Bridge configurations with different cross-frame spacing were studied using finite element modeling and simulation of the bridge behavior with a fractured steel plate girder. Nonlinear and dynamic solution methods were used for these analyses. Results of this investigation demonstrated the important role cross-frames can play in providing some reserved capacity for the bridge with fractured girder to enhance the bridge redundancy. The contribution of the cross-frames and the behavior of the bridge after fracture in one girder however depends on the configuration of the bridge. A study of the variation of the effect of cross-frames with respect to the number of girders is also included in this paper.
\end{abstract}

Keywords: steel bridges; fracture; cross-frame; redundancy evaluation; load distribution; finite element analysis

\section{Introduction}

In steel girder bridges, fatigue cracking is one of the most important phenomena affecting the structural performance and integrity [1]. In general, fatigue cracks are the result of out-of-plane distortion or other unanticipated secondary stresses at low fatigue resistance members. Development of fatigue cracking may lead in time to a full depth fracture of one girder and cracks in the deck [2] without noticeable bridge profile changes. It is critical to assure that the bridge will have adequate capacity to prevent collapse until the next cycle of inspection discovers the damage. The fracture can also be detected through instrumentation at the onset of fracture or by periodic vibration measurements at inspection intervals or earlier [3] and different strategies can be used to repair and retrofit the damaged bridge $[4,5]$. It is realized that once one of the bridge girders is fractured, vertical dead and live loads need to be distributed through an alternative path to the intact girder(s) which could occur through the deck or girder cross-frames. In this case, cross-frames can play an important role in transferring the loads and preventing sudden collapse of the fractured girder. However, currently cross-frames are required to be designed only for preventing lateral torsional buckling of the bridge girders during construction, transferring lateral loads such as wind and earthquake to the deck and from the deck to the supports for controlling torsional stresses, as well as large rotation due to loads applied to the overhangs. As a result, when fracture occurs in one girder, they may not have enough stiffness and strength and may be too far spaced to be able to transfer vertical loads to the intact girder(s). 
The impact of cross-frames on seismic response and lateral torsional buckling of steel girder bridges has been a concern among researchers [6-9]. Their investigation has had the main goal of studying the elastic and inelastic response of cross-frames during an extreme seismic event and developing new design approaches to have a plastic deformation in substructure and protecting foundation where identifying and repairing damages is difficult. The advantages of such approaches are that cross-frames which are considered as secondary members during the bridge normal operation, can be replaced after extreme seismic events. However, cross-frames can increase the risk of distortion-induced fatigue cracking in the bridge girders during the bridge normal operation under the traffic loading [10]. As a result, many investigations have been performed on the mitigation of distortion-induced fatigue problem [11] and new construction techniques such as permanent metal deck forms are developed to minimize the number of intermediate cross-frames along the span of steel bridges [12]. Nevertheless, it is believed that cross-frames can play an important role as an alternative load path after the girder fracture due to fatigue and corrosion related defects [13]. Therefore, optimum spacing and stiffness of braces could decrease the consequence of fracture and increase the bridge reserved capacity after the fracture.

Recent studies on the reserved capacity of bridges and redundancy evaluation have mainly focused on the steel I-girder and box-girder bridges with a partial or full-depth fracture of one of the girders [14-25]. The results of these studies demonstrated a high level of internal redundancy and secondary load paths in the bridge systems. Moreover, a study on the fracture critical bridges summarized examples of steel bridges that survived even after a full-depth fracture in one of the girders [26].

Limited studies have also been performed on the connection details of cross-frames [27] and the effect of lateral bracing and buckling of main girders after a fracture. Four types of cross-frame connection details, including the use of end-plate connection, connection plate and split-tee connection were experimentally investigated by Takahashi et al. [28]. Kozy and Tunstall [29] conducted stability analysis on a steel girder bridge. His results showed that system or global buckling is the failure mode of non-composite girder systems without lateral cross-frame. Shi [30] numerically studied the effective parameters on the stability and capacities of I-girder bridges. Parameters considered in this study included flange width to thickness ratio, girder depths, web depth to thickness ratio, number of stiffeners along the span and cross-frame spacing. The effect of lateral cross-frames in continuous span plate-girder bridges with a full-depth fractured girder was considered in the investigations by Park et al. [15]. The test results showed that the ultimate capacity of damaged bridge with bracing was about 1.2 times higher than the bridge without bracing. The numerical analysis indicated that the bottom chord of cross-frames plays an important role in transferring vertical loads from the fractured girder to the intact girder.

In the American Association of State Highway Transportation Officials (AASHTO) LRFD Bridge Design Specifications [31], the arbitrary requirement for cross-frame at no more than $25 \mathrm{ft}$ has been replaced by a requirement for rational analysis to prevent the development of fatigue cracking in the girders at the connections of lateral bracing due to out-of-plane distortion. However, no guidance has been provided for the requirements of such an analysis. Therefore, the cross-frame spacing is generally determined based on the stability bracing during construction and in many cases, typical sizes and details are used for cross-frames which can lead to either inadequate brace spacing and stiffness or braces that are stiffer than necessary.

This paper investigates the impact of cross-frames on load distribution after a fracture is occurred in one girder. Since in this situation, the cross-frame members resist forces that are critical to the proper performance of the damaged bridge, they may need to be considered primary members. Therefore, forces in the bracing members need to be computed and considered in designing these members for preventing the bridge from sudden partial or total collapse. This study includes computational analysis using finite element models that are validated against existing laboratory test results to investigate the effect of cross-frames. A simple span, three I-girder bridge tested at the University of 
Nebraska-Lincoln [32] was selected as a case study for the finite element (FE) analysis. This bridge for which elastic and ultimate load data are available from the tests was deemed to be a perfect candidate for validation of the FE model. The effect of cross-frames with different spacing was investigated for the bridge model with a full depth fracture of one of the exterior girders at the mid-span to simulate the worst-case scenario. The bridge was loaded incrementally over the fractured girder as a function of multiples of the AASHTO Live load including the design truck and lane load, until the bridge collapsed.

\section{Finite-Element Analysis and Overview of Study}

Finite element analysis of bridges, both in intact and damaged conditions, offers a reliable method for simulating the behavior of bridges and a credible alternative to costly experiments [33-37]. However, even with this valuable numerical tool, elaborate modeling of a bridge and detailed analysis under various loading requires significant time and efforts. It should be recognized that it may not be necessary nor economic to model the bridge with every detail and variations. The more sophisticated the model is, the more is potential for divergence of the solution and unwanted errors. Finding the optimum model requires experience and knowledge in implementing FE modeling [38] and requires validation using existing detailed and reliable experimental results.

In this study, to investigate the effects of cross-frames on the behavior of bridge with fracture in one girder, a well performed and documented set of experimentation on a full-scale I-girder bridge specimen tested at the University of Nebraska-Lincoln was chosen. For this bridge specimen, Abaqus Standard 6.14-2 [39], FE analysis program, was used to develop a detailed model. The model was then validated with the help of available test results for this bridge.

This bridge had a simple span with a length of $21.3 \mathrm{~m}(70 \mathrm{ft})$ and width of $7.9 \mathrm{~m}(26 \mathrm{ft})$ and would carry two lanes of traffic. Three welded steel plate girders was used for superstructure that was made composite with a $0.2 \mathrm{~m}\left(7^{\frac{1}{2}} \mathrm{in}\right.$.) deck made of reinforced concrete as shown in Figure 1. The spacing of

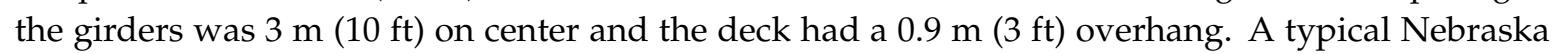
Department of Road (NDOR) concrete railing system with an open profile and using $0.3 \times 0.3 \mathrm{~m}(11 \times$ $11 \mathrm{in}$.) posts with a spacing of $2.4 \mathrm{~m}(8 \mathrm{ft})$ on center was used as the railing system. To investigate the contribution of the cross-frames, a set of laboratory tests were carried out on this bridge. The loading was increased incrementally to cover both the elastic and ultimate plastic behavior of the bridge. The steel plate girders were kept intact before the test, that is, no fractured girder was used. Among the test performed on this bridge, the test in which the bridge was loaded to failure (ultimate test) was selected for validation of the FE model. In this test, point loads representing footprint of HS20 Truck loading were incrementally increased until the failure. The failure reported for this bridge in the laboratory testing was dominated by punching shear failure of the deck.

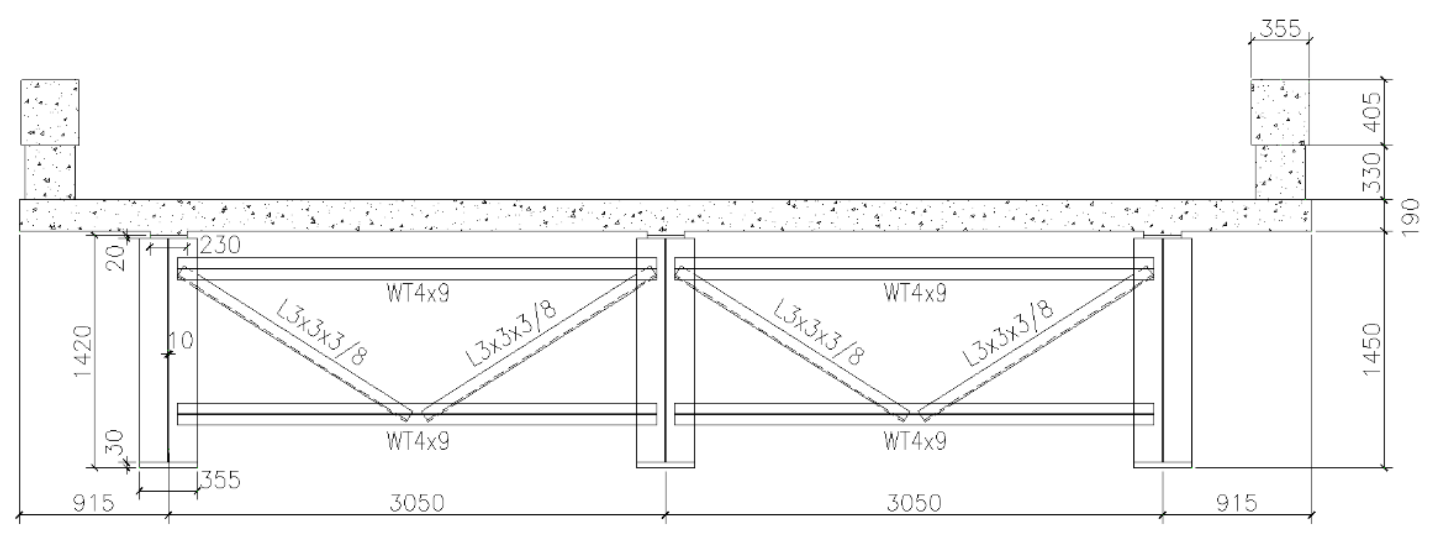

Figure 1. University of Nebraska-Lincoln I-Girder Bridge (Dimensions are in mm).

After validation of the FE model, a full-depth fracture of one of the exterior girder at the middle of span was implemented in the bridge model as shown in Figure 2. In order to create the maximum 
bending and torsion over the fractured girder, only one lane of the bridge immediately above the fractured girder was loaded incrementally until the failure in the terms of AASHTO Live loads (HL93) to simulate eccentric loading caused by disruptions [40,41] or safety issues [42], that is a combination of design truck and lane load. Failure was defined by the plateau in load-displacement curve signaling loss of capacity to carry higher loads. Different cross-frame spacing (i.e., different number of cross-frames within the span), as shown in Figure 3, was used and the results were compared to investigate the effect of cross-frame in load distribution, ultimate capacity and the bridge deflection.

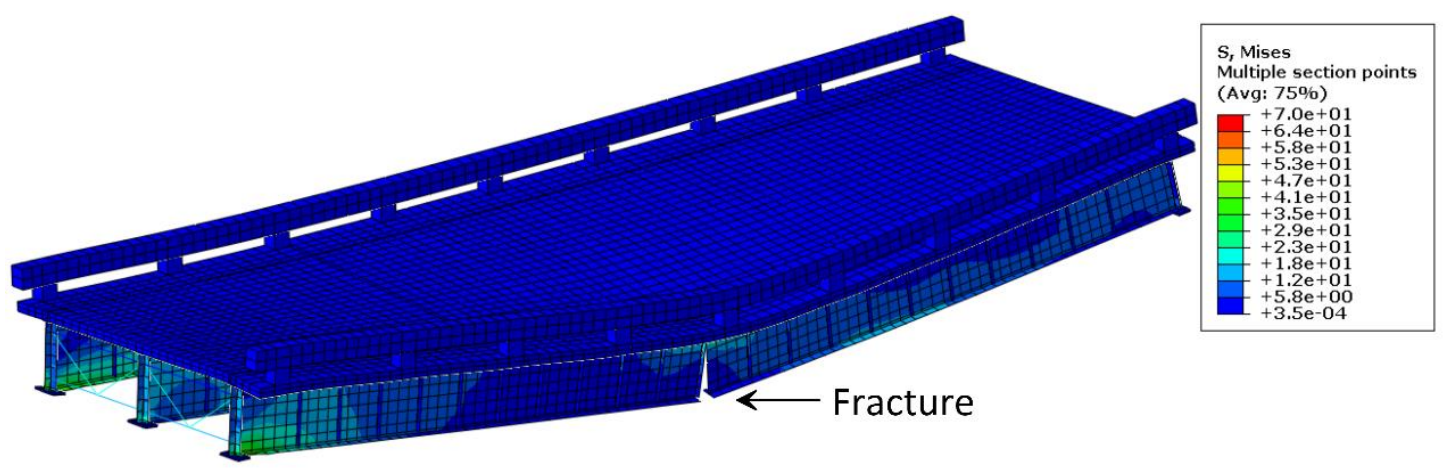

Figure 2. Finite element (FE) model of the fractured bridge.

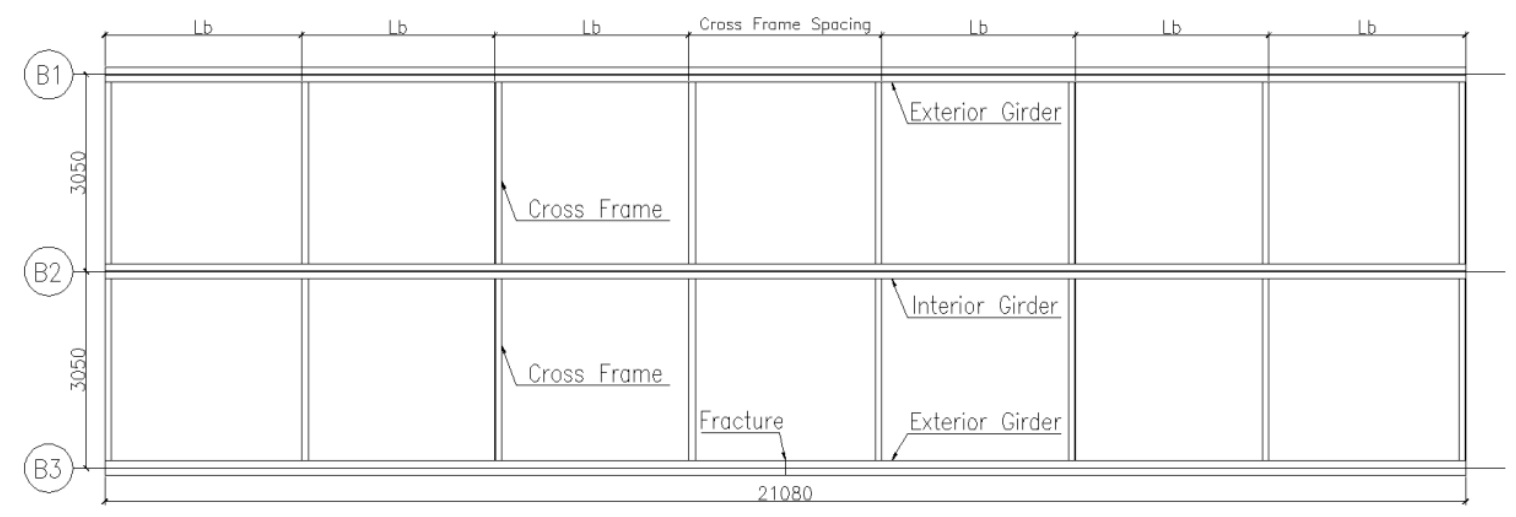

Figure 3. The bridge layout and cross-frame spacing.

\section{Finite Element Model}

Steel plates, cross-frames and reinforcement were modeled using multi-linear inelastic material with isotropic hardening in both tension and compression. The modulus of elasticity $(200,000 \mathrm{MPa})$ and Poisson's ratio (0.3) were used for defining the linear elastic behavior. The steel material used for the girders was specified as A36 steel with yield strength of $276 \mathrm{MPa}$ (average obtained from the tensile testing (40 ksi)) and the concrete reinforcing rebar used in the concrete slab was specified as Grade 60 with $414 \mathrm{MPa}(60 \mathrm{ksi})$ yield strength. An effective damping ratio of $3 \%$ was assigned to the steel and concrete materials for the dynamic analysis and a linear elasticity with damage plasticity constitutive model [43] was used for the concrete elements. ACI 318-14 [44] was utilized for calculating the initial modulus of elasticity in concrete materials with a Poisson ratio of 0.2 . The strength tests on concrete cylinder samples showed $41 \mathrm{MPa}$ (6 ksi) for 221 days after casting which coincides the time of ultimate load testing. This strength was used as the concrete compressive strength.

According to the structural behavior of each component, various types of elements were used to provide a realistic representation of the steel plate girder bridges. 8-node linear brick elements were used for the concrete deck and railing with 2-node linear 3-D truss elements as the reinforcement embedded into the concrete elements. Two elements were used through the deck thickness which showed a good agreement with the experimental results. 4-node shell element (S4R) was used for 
modelling steel plate girders and stiffeners and all the brace members for diaphragms were modeled using 2-node linear 3-D truss and beam elements. Refined mesh was used near the fracture at mid-span.

Experimental tests on fractured bridges show that when the loading is applied eccentrically over the fractured girder only, torsional moment induced by the loading eccentricity may cause uplift of the intact girder over the supports [17]. Therefore, to consider the possibility of support uplift during the loading and considering contact interactions, contact surface was defined between the girders and supports. In addition, connector elements were used to connect the cross-frames to the girders and simulate the connection failure at the cross- frames. As a result, the section at the end of the bracing members can be treated as a fuse with an assigned failure criteria based on the load level that will produce failure of the connection. In this study, this level of load was considered to be one half of the member tension capacity based on the typical connection details used in the experimental test (The bolts connecting the cross-frame to the girders in the experimental test consisted of 4 high strengths, A325 bolts with 7/8-inch diameter).

In the first FE model, the interaction between the shear studs and the concrete deck were modeled to simulate the possibility of shear stud failure in the bridge. Connector element was utilized for modeling the shear studs. The ultimate shear and tension capacity for the connector elements were assigned based on the shear and pull-out test conducted by Topkaya [45] and the University of Texas [46]. Once the shear or tension force in the shear stud element reaches to its capacity, the element would lose its connection to simulate the pull-out or shear failure. The FE analysis showed that the cross-frames connections fail only after $0.12 \mathrm{~m}$ girder deflection after which, the shear stud failure occurs on a limited length of the deck over the fractured girder due to the excessive girder deflection and pull-out force created in the studs. Since this study focuses on the impact of the cross-frame on the fractured bridge and the shear stud failure could happen after the cross-frame failure, it was concluded that modelling the shear stud failure does not have any significant effect on the results of this study. Therefore, to reduce the computational cost, the shear studs were not modeled in the FE analysis.

\section{Finite Element Validation}

A two-stage loading and simulation scheme was used for FE modeling of the bridge through the construction process. This included the stage where the fresh concrete is placed in the deck and the stage after hardening of the deck concrete. The first stage corresponds to steel girders carrying the entire dead load and the second stage corresponds to additional load carried out by the composite action of the girders and the deck. These conditions were modeled by varying the stiffness and mass of the concrete before and after hardening of the concrete. The first stage was used as initial stage for starting the second stage. Details of this modeling process can be found in the work by Abedin and Mehrabi [3]. The FE model was analyzed for the construction stage and subsequent point loading as reported for the laboratory tests on the University of Nebraska-Lincoln Bridge experiments. Experimental and FE analysis results for load-deflection are compared in Figure 4. The results are shown for deflection of both interior and exterior girders. The live loading in the FE model followed exactly the configuration reported for the experimental test mimicking (with a slight deviation on spacing from) the HS20 Truck loading at wheel footprints. The truck loading was applied in the FE model using a uniform pressure on the wheel footprints at the deck. Deflection noted on Figure 4 refers to the vertical displacement of the bottom flange of the girders at the mid-span. The total load referenced in Figure 4 is calculated as the sum of the point loads applied on the deck. The results show a good agreement between the load-deflection curves from laboratory tests and FE analysis, indicating the ability of the FE model for simulating the elastic and plastic global behavior of the bridge. Load-deflection curve obtained from FE analysis for the exterior girder (Figure $4 b$ ) shows slight departure from the experimental results in the plastic region. This can be attributed partly to the modeling accuracy for contribution of the railing in the deflection of the exterior girder. Overall, the load-deflection curves from FE analysis agree well with the experimental results. The FE model was also able to predict the local failures such as cracking in the railing and punching shear in the deck. It should be noted that since the concrete cylinder test 
results for the experimental test varied from $39 \mathrm{MPa}(5.66 \mathrm{ksi})$ to $45.3 \mathrm{MPa}(6.57 \mathrm{ksi})$ in 221 days after casting (the time of ultimate load testing), for the FE analysis in this study, the average value of $41 \mathrm{MPa}$ (6 ksi) was considered for the concrete compressive strength of the deck and railings. Because of the effect of railing, variation of the concrete properties in the analysis from the actual properties can have larger effect on deflection of the exterior girder than that of the interior girder.

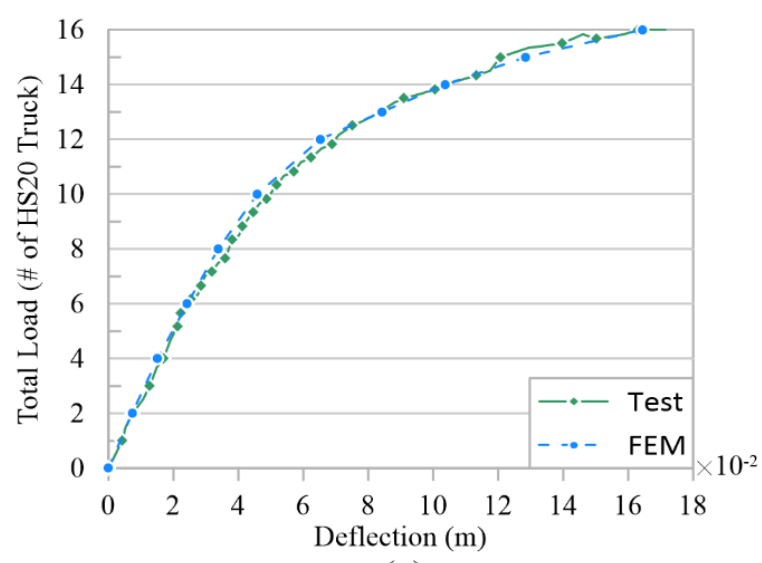

(a)

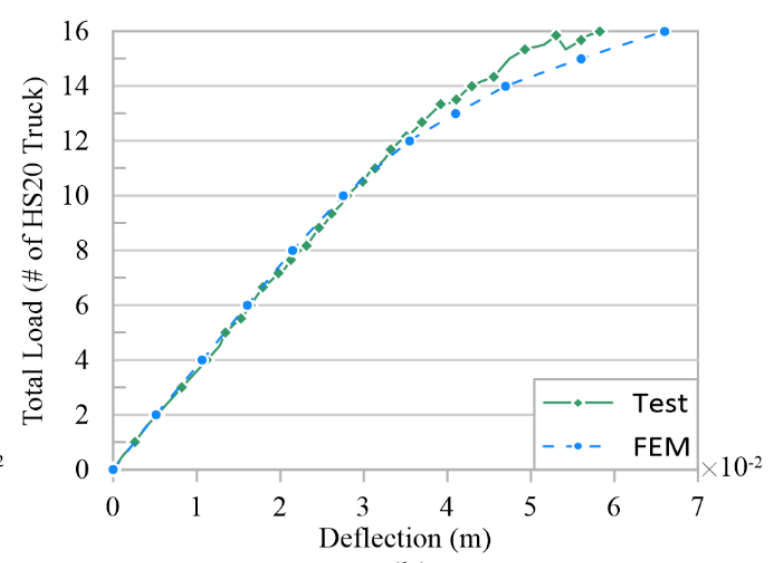

(b)

Figure 4. Finite element validation using load- deflection curves obtained from the test. (a) Interior Girder and (b) Exterior Girder.

\section{Results and Discussion}

The goal of this study was to investigate the effect of cross-frames on load distribution, ultimate capacity and the bridge deflection. A three I- girder bridge with a full-depth fracture of an exterior girder under the dead load and an increasing live load in terms of multiple of HL93 loading was modeled with different cross-frames spacing ranging from $1.8 \mathrm{~m}$ to $9 \mathrm{~m}$ (Figure 5). These cases included five different spacing, a case with no cross-frame and a case with no intermediate cross-frame as shown in Table 1. The cross-frames configuration and element sizes were modeled as shown in Figure 1. The live load was applied over the fractured girder to simulate the worst-case scenario. It is realized that small spacing for cross-frame be viewed to be uneconomic in practice but nevertheless considered in this study for the sake of parametric evaluation.

Table 1. Girder deflection at mid-span under the dead and 2 times HL93 loading.

\begin{tabular}{|c|c|c|c|c|c|c|c|c|}
\hline & & \multicolumn{7}{|c|}{ Dead Load + Live Load $(2 \times$ HL93) } \\
\hline \multirow{2}{*}{\multicolumn{2}{|c|}{ Girder }} & \multicolumn{5}{|c|}{ Intermediate Cross-Frame Spacing (m) } & \multirow{2}{*}{$\begin{array}{c}\text { No } \\
\text { Cross-Frame }\end{array}$} & \multirow{2}{*}{$\begin{array}{l}\text { No Intermediate } \\
\text { Cross-frame }\end{array}$} \\
\hline & & 1.8 & 3.6 & 5.4 & 7.2 & 9 & & \\
\hline \multirow{2}{*}{$\begin{array}{l}\text { Ext. Girder } \\
\text { (Fractured) }\end{array}$} & Deflection $(\mathrm{mm})$ & 74.8 & 76.4 & 77.9 & 79.6 & 79.6 & 102.6 & 80.9 \\
\hline & Ratio (\%) & 7.50 & 5.54 & 3.66 & 1.55 & 1.54 & -26.82 & - \\
\hline \multirow{2}{*}{ Int. Girder } & Deflection $(\mathrm{mm})$ & 37.3 & 36.7 & 36.4 & 36.3 & 36 & 39.2 & 35.5 \\
\hline & Ratio (\%) & -4.92 & -3.26 & -2.60 & -2.29 & -1.36 & -10.38 & - \\
\hline \multirow{2}{*}{ Ext. Girder } & Deflection $(\mathrm{mm})$ & 16.3 & 16.8 & 17.2 & 17.4 & 17.7 & 13.6 & 18.2 \\
\hline & Ratio (\%) & 10.10 & 7.31 & 5.32 & 4.23 & 2.60 & 25.19 & - \\
\hline
\end{tabular}

Note: Ratio = Percentage of change (deflection to No Intermediate Cross-Frame deflection); Ext. = Exterior; Int. = Interior. 


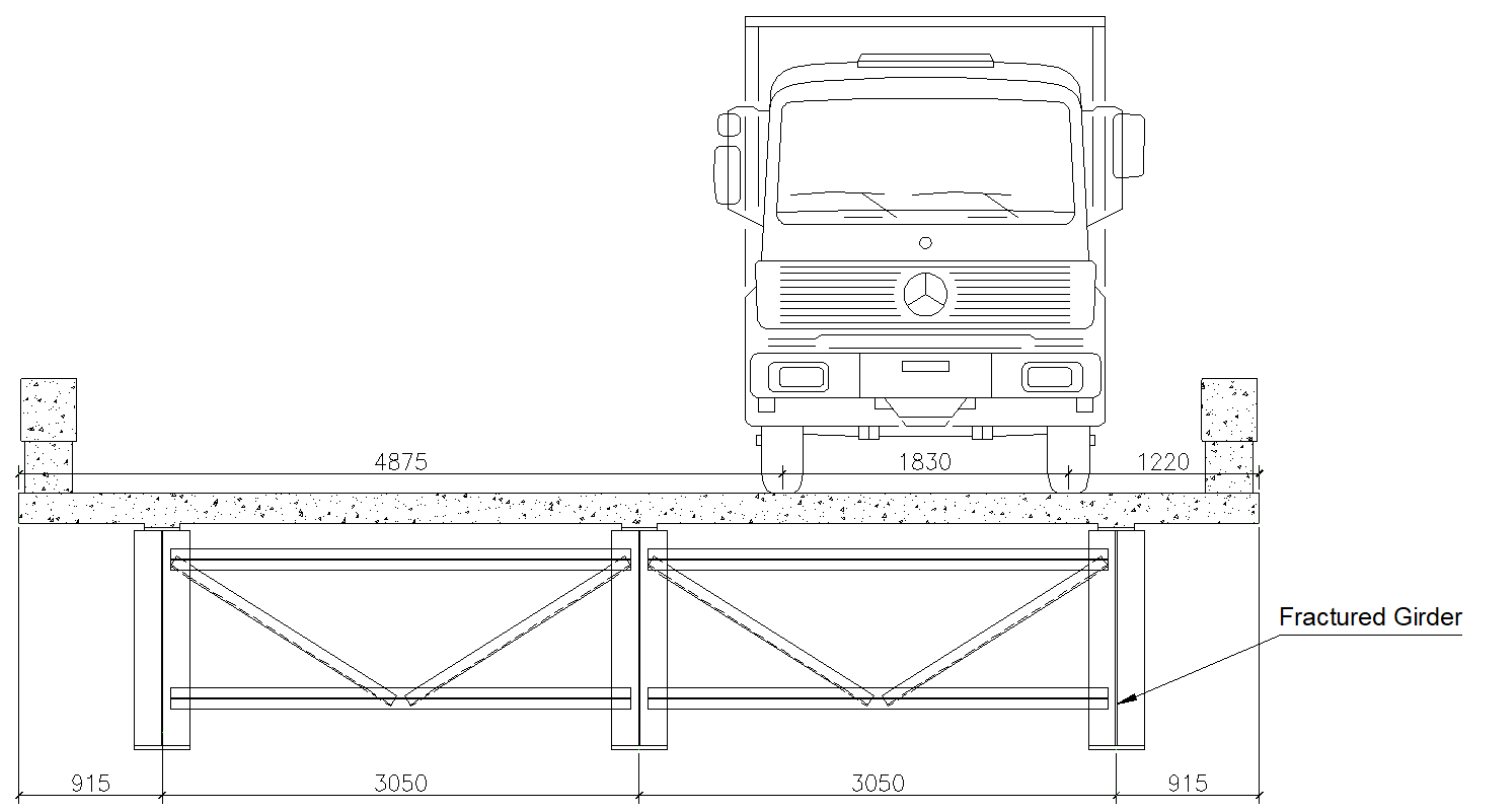

Figure 5. The position of HL93 loading over the fractured girder (Dimensions are in mm).

Using FE analysis, the deflection at the mid-span of all the three girders under the dead load and twice the HL93 loading were obtained for the bridges with different intermediate cross-frame spacing and removing all the cross-frames including the end cross-frames (No Cross-Frame). The results (Table 1) show that the deflection of the fractured girder reaches up to $80.9 \mathrm{~mm}$ at the mid-span when there is no intermediate cross-frame. It also shows that this deflection can be decreased by $7.5 \%$ when using intermediate cross-frame with $1.8 \mathrm{~m}$ spacing. Moreover, the cross-frames enable the bridge to deflect more uniformly for all the girders by transferring the vertical loads from the fractured girder to the intact girders. The results show that the deflection of the interior girder increases by $4.92 \%$ by decreasing the cross-frame spacing that indicates the cross-frames transfer vertical loads from the fractured girder to the interior girder.

To investigate the global behavior of the fractured bridge, load-deflection curves for different cross-frame spacing layouts were obtained and are shown in Figure 6. In this figure, deflection refers to vertical displacement of fractured girder at the mid-span and was obtained using finite element method (FEM) and the live load refers to increasing load in terms of multiple of combination of lane load and HS20 truck over the fractured girder (One lane loading). It can be concluded from the results that decreasing the cross-frame spacing, increases the initial stiffness of the fractured bridge. Experimental investigation by Kathol et al. [32] has demonstrated that the cross-frames have negligible impact on the global behavior of the intact bridge, and they begin carrying vertical load once a fracture occurs. The first plateau in the load-deflection curves corresponds to the failure of the cross-frames close to the fracture. The results show that intermediate cross-frames used in this study (WT4 $\times 9$ top and bottom chords and L3 $\times 3 \times 3 / 8$ diagonals) can transfer vertical load as an alternative load path to the intact girders for up to 3.6 times HL93 depending on the cross-frame spacing. This level of loading corresponds to the failure of the cross-frame connections.

Axial forces in the bottom and top chords of the cross-frames between the fractured and interior girders under dead load and one-time HL93 are shown in Table 2. The intermediate cross-frames are numbered along the span for each case, for example, the bridge with $1.8 \mathrm{~m}$ cross-frame spacing has 10 intermediate cross-frames. The results indicate that axial forces in the end cross-frame are constant in all the cases of different cross-frame spacing layouts. Moreover, the forces in the end cross-frames are much higher than intermediate cross-frames, even higher than those for the cross-frames near the fracture and under the truck loading. This can be attributed to torsional force developed in the bridge after the fracture and eccentric loading. For example, in the bridge with $1.8 \mathrm{~m}$ intermediate 
cross-frame spacing, axial force in the end cross-frame is $147.7 \mathrm{kN}$. However, the maximum force in the intermediate cross-frames close to the fracture and under the truck loading is only $49.4 \mathrm{kN}$. The FE analysis shows that the end cross-frames reach to their maximum connection capacity of $220 \mathrm{kN}$ under dead load and 1.8 times HL93 in all the cases before the intermediate cross-frames. The comparison between the cross-frame axial forces indicates that cross-frames close to fracture and truck loading have noticeable contribution in transferring the vertical loads from the fractured girder to the interior girder and axial load in the cross-frames far from the fracture is negligible.

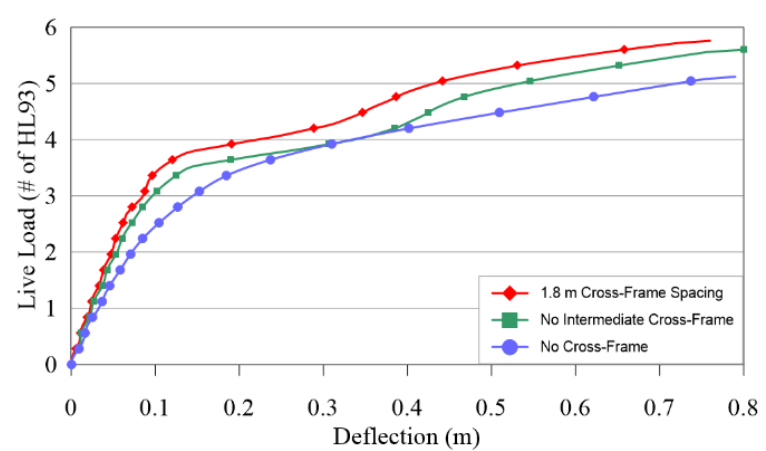

(a)

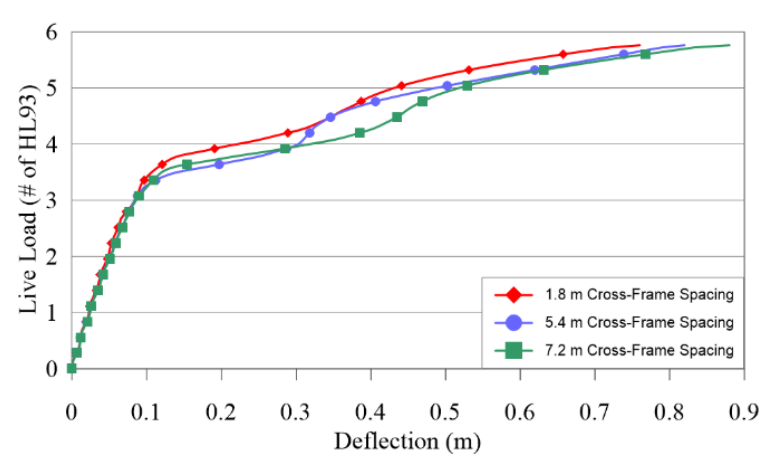

(b)

Figure 6. Load-deflection curve of the fractured girder at mid-span. (a) Different cross-frame layouts, (b) Different cross-frame spacing.

Table 2. Axial force in the cross-frames between the fractured and interior girders under dead load and one- time HL93 loading.

\begin{tabular}{|c|c|c|c|c|c|c|c|c|c|c|c|c|c|c|}
\hline \multirow{2}{*}{\multicolumn{2}{|c|}{ Spacing (m) }} & \multirow{2}{*}{ Chord } & \multirow{2}{*}{$\begin{array}{c}\text { End } \\
\text { Cross-Frame }\end{array}$} & \multicolumn{10}{|c|}{ Intermediate Cross-Frame No. } & \multirow{2}{*}{$\begin{array}{c}\text { End } \\
\text { Cross-Frame }\end{array}$} \\
\hline & & & & 1 & 2 & 3 & 4 & 5 & 6 & 7 & 8 & 9 & 10 & \\
\hline \multirow{12}{*}{ 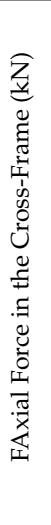 } & \multirow{2}{*}{1.8} & Top & 147.3 & 9.3 & 8.0 & 0.4 & 1.8 & 5.8 & 10.2 & 2.2 & 1.3 & 2.7 & 26.3 & 138.8 \\
\hline & & Bottom & 147.7 & 10.2 & 2.7 & 20.5 & 36.0 & 49.4 & 40.1 & 36.0 & 9.8 & 16.0 & 12.5 & 136.2 \\
\hline & \multirow{2}{*}{3.6} & Top & 146.9 & 20.5 & 3.6 & 8.5 & 7.1 & 2.2 & 25.4 & - & - & - & - & 131.7 \\
\hline & & Bottom & 146.9 & 9.3 & 12.9 & 83.2 & 85.4 & 2.2 & 32.0 & - & - & - & - & 134.4 \\
\hline & \multirow{2}{*}{5.4} & Top & 143.7 & 9.8 & 8.9 & 10.2 & 9.8 & - & - & - & - & - & - & 150.0 \\
\hline & & Bottom & 149.1 & 5.8 & 61.0 & 60.5 & 0.4 & - & - & - & - & - & - & 147.7 \\
\hline & \multirow{2}{*}{7.2} & Top & 155.3 & 9.8 & 9.8 & - & - & - & - & - & - & - & - & 149.5 \\
\hline & & Bottom & 156.2 & 69.9 & 55.2 & - & - & - & - & - & - & - & - & 146.9 \\
\hline & \multirow{2}{*}{9} & Top & 155.8 & 8.0 & 8.0 & - & - & - & - & - & - & - & - & 145.5 \\
\hline & & Bottom & 151.3 & 44.9 & 40.9 & - & - & - & - & - & - & - & - & 148.2 \\
\hline & \multirow{2}{*}{ No-Int. } & Top & 157.1 & - & - & - & - & - & - & - & - & - & - & 147.7 \\
\hline & & Bottom & 155.3 & - & - & - & - & - & - & - & - & - & - & 150.4 \\
\hline
\end{tabular}

Note: No-Int. $=$ No Intermediate Cross-Frame.

Figure 7 shows the connector element force of the cross-frame close to the fracture in the bridge with $1.8 \mathrm{~m}$ cross-frame spacing. The force in the section reaches $39.7 \mathrm{kN}$ under the dead load once a fracture occurs. This means the cross-frames contribute in carrying the dead load after the fracture and the cross-frame force reaches to its maximum connection capacity of $220 \mathrm{kN}$ under the live load equal to 3.6 times HL93 loading. After the connection failure (local plateau in the load-deflection curve) vertical loads redistribute to the remaining cross-frames and the bridge continues carrying load until the global failure (plateau in the bridge load-deflection curve). 


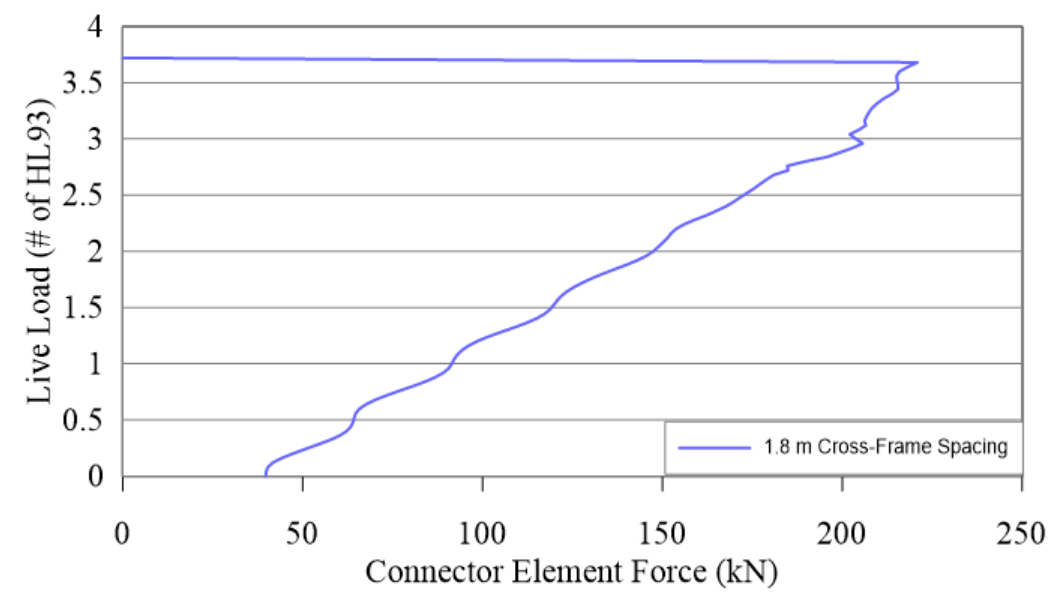

Figure 7. The connector element axial force over the loading.

Analysis of the live load distribution factor (LDF) in Table 3 shows that the cross-frame spacing has negligible effect on the live load distribution even after fracture occurred. This conclusion has been confirmed for the intact bridge in the experimental investigation by Kathol et al. [32]. However, due to fracture of the exterior girder and load eccentricity, torsional forces in the section create an uplift force in the exterior intact girder. By decreasing the intermediate cross-frame spacing, the torsional stiffness of the bridge section will increase and the bridge acts more integrated against the rotation. As a result, the uplift force in the exterior intact girder will increase. The FE results show that the uplift force in the bridge with $1.8 \mathrm{~m}$ cross-frame spacing is $25 \%$ more than the bridge with no intermediate cross-frame. The intact exterior girder begins uplift at the support when the eccentric live load reaches one time the HL93 design live load, that is, the live load uplift force equals the dead load reaction with one-time full HL93 design live load on one lane.

Table 3. Live load distribution under HL93 loading.

\begin{tabular}{|c|c|c|c|c|c|c|c|}
\hline \multirow{3}{*}{ Girder } & \multicolumn{7}{|c|}{ Live Load Distribution (HL93) } \\
\hline & \multicolumn{5}{|c|}{ Intermediate Cross-Frame Spacing (m) } & \multirow{2}{*}{$\begin{array}{c}\text { No } \\
\text { Cross-Frame }\end{array}$} & \multirow{2}{*}{$\begin{array}{l}\text { No Intermediate } \\
\text { Cross-frame }\end{array}$} \\
\hline & 1.8 & 3.6 & 5.4 & 7.2 & 9 & & \\
\hline Ext. Girder (Fractured) & 0.94 & 0.94 & 0.94 & 0.94 & 0.94 & 0.92 & 0.96 \\
\hline Int. Girder & 1.26 & 1.26 & 1.26 & 1.28 & 1.28 & 1.32 & 1.20 \\
\hline Ext. Girder & -0.20 & -0.20 & -0.20 & -0.18 & -0.18 & -0.24 & -0.16 \\
\hline
\end{tabular}

Note: Ext. = Exterior; Int. = Interior.

A very important conclusion drawn from the finite element analysis is that the end cross-frames play an important role in the fractured scenario. In this situation, live and dead loads over the fractured girder create additional torsional force in the bridge section that is transferred to the support through intact girders and intermediate cross-frames and then to the bearing using the end cross-frames. The results indicate that removing the end cross-frame, increases the girder deflection by $26.8 \%$ in the fractured bridge. As a result, these members need to be designed for carrying the torsional forces created by the dead and live load after the fracture in order to prevent excessive deflection of the girder after a fracture.

Several additional models were developed to investigate the effect of different cross-frame types other than K-bracing used in this study including X-bracing in the fractured bridge. The results indicate that different cross-frame type with the same cross-sections (WT4 $\times 9$ top and bottom chords and L $3 \times 3 \times 3 / 8$ diagonals) would not make significant differences in the girder deflection (Table 4 ). The same conclusion was reached in the experimental test by Kathol et al. [32] on the intact bridge. 
Table 4. Girder deflection at mid-span under the dead and 2 times HL93 loading for different cross-frame types.

\begin{tabular}{ccccc}
\hline \multirow{2}{*}{ Cross-Frame Type } & \multicolumn{4}{c}{ Dead Load + Live Load (2 $\times$ HL93) } \\
\cline { 2 - 5 } & Cross-Frame Spacing & Exterior Girder (fractured) & Interior Girder & Exterior Girder \\
\hline K-Bracing & 5.4 & 77.9 & 36.4 & 17.2 \\
\hline X-Bracing & 5.4 & 77.6 & 36.2 & 17.1 \\
\hline No Cross-Frame & 5.4 & 102.6 & 39.2 & 13.6 \\
\hline
\end{tabular}

To investigate the impact of cross-frames after a fracture in bridges with different number of longitudinal girders, additional models were developed representing twin I-girder bridges (Figure 8). Twin-girder bridges because of their configuration are classified as non-redundant structure where fracture in one girder may cause the bridge to collapse. The bridge dimensions, properties and loading were considered the same as the three I-girder bridge except the number of girders and the corresponding width. Similar parametric analysis was conducted to compare the bridge behavior with different cross-frame spacing in the twin I-girder bridges. Table 5 shows the girder deflection for the twin I-girder bridge. The results show that the deflection of the fractured girder (Right Girder) reaches up to $220.4 \mathrm{~mm}$ at the mid-span under dead and two times HL93 design load when there is no cross-frame. By adding the end cross-frames (No intermediate cross-frame model) the fractured girder deflection decreases by $24.7 \%$ which shows the contribution of end cross-frames in the damaged bridge. Moreover, intermediate cross-frames can decrease the bridge deflection up to $9.5 \%$ when the $1.8 \mathrm{~m}$ spacing is used.

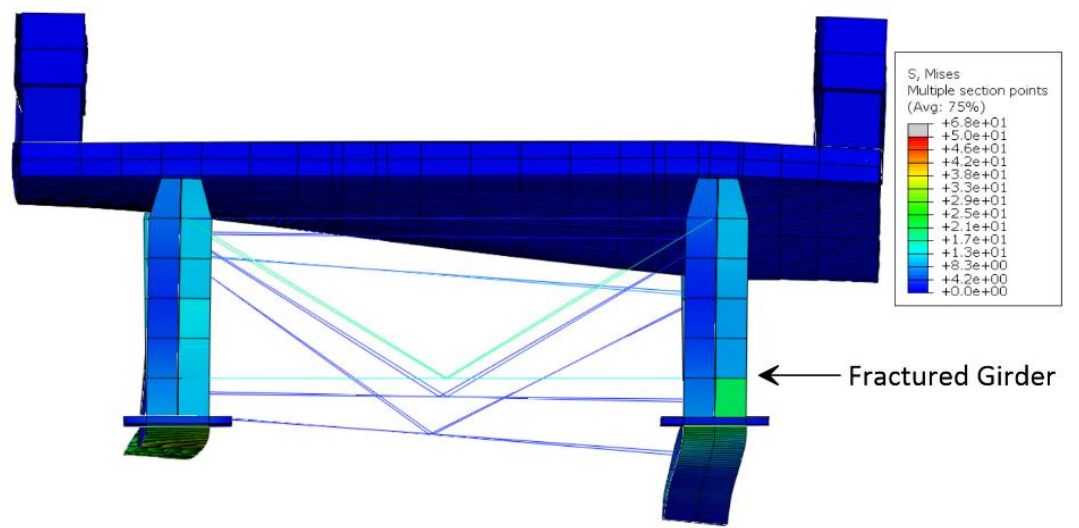

Figure 8. Finite Element Model of the fractured twin I-girder bridge.

Table 5. Girder deflection of the twin I-girder bridge at mid-span under the dead and 2 times HL93 loading.

\begin{tabular}{|c|c|c|c|c|c|c|c|c|}
\hline \multirow{3}{*}{\multicolumn{2}{|c|}{ Girder }} & \multicolumn{7}{|c|}{ Dead Load + Live Load $(2 \times$ HL93) } \\
\hline & & \multicolumn{5}{|c|}{ Intermediate Cross-Frame Spacing (m) } & \multirow{2}{*}{$\begin{array}{c}\text { No } \\
\text { Cross-Frame }\end{array}$} & \multirow{2}{*}{$\begin{array}{l}\text { No Intermediate } \\
\text { Cross-frame }\end{array}$} \\
\hline & & 1.8 & 3.6 & 5.4 & 7.2 & 9 & & \\
\hline \multirow{2}{*}{$\begin{array}{l}\text { Right Girder } \\
\text { (Fractured) }\end{array}$} & Deflection $(\mathrm{mm})$ & 159.8 & 162.8 & 163.8 & 164.6 & 165.5 & 220.4 & 176.7 \\
\hline & Ratio (\%) & 9.5 & 7.8 & 7.3 & 6.8 & 6.3 & -24.7 & - \\
\hline \multirow{2}{*}{ Left Girder } & Deflection $(\mathrm{mm})$ & 47.0 & 47.4 & 46.9 & 45.7 & 46.2 & 48.7 & 44.6 \\
\hline & Ratio (\%) & -5.4 & -6.3 & -5.1 & -2.4 & -3.6 & -9.0 & - \\
\hline
\end{tabular}

Note: Ratio = Percentage of change (deflection to No Intermediate Cross-Frame deflection); Ext. = Exterior; Int. $=$ Interior.

A comparison between the girder deflection shows that the fractured girder deflection in the twin I-girder bridge is more than twice that of the fractured girder in the three I-girder bridge in all 
the cases under the same loading and cross-frame layout. However, deflection of the intact girder in the twin I-girder bridge only increased by an average of $27 \%$ compared to the intact girders in the three I-girder bridge. For example, in the twin I-girder bridge with $5.4 \mathrm{~m}$ cross-frame spacing, the fractured and intact girder deflection are $163.8 \mathrm{~mm}$ and $46.9 \mathrm{~mm}$, respectively. However, these deflections in the three I-girder bridge is only $77.9 \mathrm{~mm}$ and $36.4 \mathrm{~mm}$. The predominant reason is that in the three I-girder bridges, after a fracture in one of the girders, the two remaining intact girders with the cross-frames demonstrate a behavior similar to a box girder with a higher torsional stiffness than two single girders without the cross-frames. This allows for a better distribution of the torsional forces from the eccentric loading and less displacement than the case of two I-girder bridges. On the other hand, in the two-girder bridges, eccentric loading pronounced after the fracture in one girder causes excessive deflection in the fractured girder due to low torsional stiffness contribution from the intact girder. Hence, the result confirms that the cross-frames can increase the torsional strength of the bridge deck against eccentric loading.

Analyzing the finite element results also indicates that in the three I-girder bridge, because of the high torsional stiffness of the combination of the two intact girders with cross-frames, there is negligible rotation about the interior girder and the concrete deck above the cross-frames carries some of the vertical load in the transvers direction as a cantilever beam. On the other hand, in the twin I-girder bridge, concrete deck has less contribution as the second load path due to the rotation about the fractured girder. As a result, the deflection of the twin I-girder bridge is more sensitive to the cross-frame spacing compared to the three I-girder bridge bringing higher contribution by the cross-frames when compared to the three-girder bridge.

The results show that axial forces in the cross-frames for the twin I-girder bridges are less than the bridge with three I-girder. This can be attributed to the rotation of the bridge about the intact girder under eccentric loading (Table 6), that is, low torsional stiffness from the intact girder. As an example, the axial forces in the intermediate cross-frames under the truck loading in the bridges with $5.4 \mathrm{~m}$ cross-frame spacing are $32 \mathrm{kN}$ and $19.1 \mathrm{kN}$ in the twin I-girder bridge, however, these forces in the three I-girder bridge are $61 \mathrm{kN}$ and $60.5 \mathrm{kN}$ (More than double). This could be because in the twin I-girder bridge a large portion of the load is transferred longitudinally to the support of the fractured girder after excessive deflection, where in the three I-girder bridge because of the high torsional stiffness, cross-frames carry the loads from the fractured girder to the intact girders transversely and then to the supports.

Table 6. Axial force in the cross-frames under dead load and one- time HL93 loading in the Twin I-girder bridge.

\begin{tabular}{|c|c|c|c|c|c|c|c|c|c|c|c|c|c|c|}
\hline \multirow{2}{*}{\multicolumn{2}{|c|}{ Spacing (m) }} & \multirow{2}{*}{ Chord } & \multirow{2}{*}{$\begin{array}{c}\text { End } \\
\text { Cross-Frame }\end{array}$} & \multicolumn{10}{|c|}{ Intermediate Cross-Frame No. } & \multirow{2}{*}{$\begin{array}{c}\text { End } \\
\text { Cross-Frame }\end{array}$} \\
\hline & & & & 1 & 2 & 3 & 4 & 5 & 6 & 7 & 8 & 9 & 10 & \\
\hline \multirow{12}{*}{ 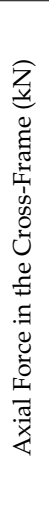 } & \multirow{2}{*}{1.8} & Top & 117.9 & 6.2 & 2.8 & 6.2 & 12.0 & 25.1 & 21.1 & 11.3 & 3.5 & 1.3 & 12.6 & 121.5 \\
\hline & & Bottom & 123.7 & 8.3 & 0.1 & 11.6 & 18.7 & 40.0 & 37.6 & 4.8 & 3.4 & 1.5 & 21.8 & 121.9 \\
\hline & \multirow{2}{*}{3.6} & Top & 115.3 & 12.0 & 2.4 & 10.2 & 9.8 & 5.3 & 23.6 & - & - & - & - & 115.3 \\
\hline & & Bottom & 121.5 & 15.1 & 12.5 & 40.9 & 34.3 & 0.8 & 27.6 & - & - & - & - & 113.5 \\
\hline & \multirow{2}{*}{5.4} & Top & 118.1 & 0.1 & 0.3 & 3.8 & 14.2 & - & - & - & - & - & - & 120.6 \\
\hline & & Bottom & 123.7 & 4.5 & 32.0 & 19.1 & 24.0 & - & - & - & - & - & - & 120.6 \\
\hline & \multirow{2}{*}{7.2} & Top & 119.7 & 4.4 & 1.9 & - & - & - & - & - & - & - & - & 127.7 \\
\hline & & Bottom & 125.9 & 32.9 & 10.7 & - & - & - & - & - & - & - & - & 128.6 \\
\hline & \multirow{2}{*}{9} & Top & 120.2 & 8.0 & 4.9 & - & - & - & - & - & - & - & - & 129.0 \\
\hline & & Bottom & 126.4 & 19.1 & 4.9 & - & - & - & - & - & - & - & - & 129.9 \\
\hline & \multirow{2}{*}{ No-Int. } & Top & 119.3 & - & - & - & - & - & - & - & - & - & - & 130.4 \\
\hline & & Bottom & 125.5 & - & - & - & - & - & - & - & - & - & - & 131.5 \\
\hline
\end{tabular}




\section{Conclusions}

A numerical investigation was carried out to study the effect of cross-frames on load distribution and global behavior of steel I-girder bridges when one of the girders is fractured. Detailed finite element models with different cross-frame spacing were developed and analyzed under dead load and increasing HL93 live load eccentrically applied in one lane over the fractured girder. The following conclusions and findings can be drawn from the results for the simple span multiple steel plate girder bridge investigated in this study:

- An adequate cross-frame spacing, and stiffness could decrease the bridge excessive deformation after a sudden fracture e in one girder and has the potential to enhance the bridge redundancy.

- The cross-frames increase the bridge torsional stiffness after fracture of one girder and enable the bridge to deflect more uniformly by transferring the vertical loads from the fractured girder to the intact girders.

- The typical cross-frame used in this study has enough stiffness to be considered as an alternative load path after a sudden fracture. This was verified for live loading of up to 3.6 times HL90 loading for $1.8 \mathrm{~m}$ spacing of the cross-frames in the three I-girder bridge.

- In three I-girder bridges, after a fracture in one of the girders, two remaining intact girders with the cross-frames between demonstrate behavior similar to a box girder with a higher torsional stiffness than two single girders without the cross-frames. This allows for a better distribution of the torsional forces from the eccentric loading and less displacement than the case of two I-girder bridges.

- In the twin I-girder bridge, fracture in one girder results in significantly larger displacements in the fractured and intact girders compared to the three I-girder bridges. The effect of cross-frames however is more pronounced in twin I-girder bridges. The elements of the cross frames in the twin I-girder bridge carry smaller forces than those in the three I-girder bridge because of larger rotation of the intact girder. A large portion of the loads for twin I-girder bridge after fracture of one girder seems to be transferred longitudinally to the support after excessive deflection, however, in the three I-girder bridge because of the high torsional stiffness cross-frames carry the loads from the fractured girder to the intact girders transversely and then to the supports.

- A very important conclusion is that the end cross-frames can play an important role in the fractured scenario and to be effective for the case of fractured girder, they will need to be designed for carrying the torsional forces created by the dead and live loads after the fracture.

Author Contributions: Conceptualization, A.B.M. and M.A.; Methodology, A.B.M. and M.A.; Validation, M.A.; Formal Analysis, M.A.; Investigation, A.B.M. and M.A.; Resources, A.B.M. and M.A.; Data Curation, M.A; Writing-Original Draft Preparation, M.A.; Writing-Review and Editing, A.B.M.; Visualization, M.A.; Supervision, A.B.M. All authors have read and agreed to the published version of the manuscript.

Funding: This research received no external funding.

Acknowledgments: The authors greatly acknowledge the internal support by the Department of Civil and Environmental Engineering at Florida International University. The contents of this paper reflect the views of the authors, who are responsible for the facts and the accuracy of the information presented herein.

Conflicts of Interest: The authors declare no conflict of interest.

\section{References}

1. Yu, J.; Ziehl, P.; Zrate, B.; Caicedo, J. Prediction of fatigue crack growth in steel bridge components using acoustic emission. J. Constr. Steel Res. 2011, 67, 1254-1260. [CrossRef]

2. Garber, D.; Shahrokhinasab, E. Performance Comparison of In-Service, Full-Depth Precast Concrete Deck Panels to Cast-in-Place Decks; Accelerated Bridge Construction University Transportation Center (ABC-UTC): Miami, FL, USA, 2019.

3. Abedin, M.; Mehrabi, A.B. Novel Approaches for Fracture Detection in Steel Girder Bridges. Infrastructures 2019, 4, 42. [CrossRef] 
4. Valikhani, A.; Azizinamini, A. Experimental Investigation of High Performing Protective Shell Used for Retrofitting Bridge Elements; Accelerated Bridge Construction University Transportation Center (ABC-UTC): Miami, FL, USA, 2018.

5. Valikhani, A.; Jahromi, A.J.; Mantawy, I.M.; Azizinamini, A. Experimental evaluation of concrete-to-UHPC bond strength with correlation to surface roughness for repair application. Constr. Build. Mater. 2020, 238, 117753. [CrossRef]

6. Carden, L.P.; Itani, A.M.; Buckle, I.G. Seismic Performance of Steel Girder Bridges with Ductile Cross Frames Using Single Angle X Braces. J. Struct. Eng. 2006, 132, 329-337. [CrossRef]

7. Itani, A.M.; Bruneau, M.; Carden, L.; Buckle, I.G. Seismic Behavior of Steel Girder Bridge Superstructures. J. Bridg. Eng. 2004, 9, 243-249. [CrossRef]

8. Lindquist, W.; Ibrahim, A.; Tung, Y.; Motaleb, M.; Tobias, D.; Hindi, R. Distortion-Induced Fatigue Cracking in a Seismically Retrofitted Steel Bridge. J. Perform. Constr. Facil. 2016, 30, 04015068. [CrossRef]

9. Dolati, A.; Maleki, S. Ductile behavior of existing internal end diaphragms in steel tub girder bridges. J. Constr. Steel Res. 2019, 153, 356-371. [CrossRef]

10. Hassel, H.L.; Bennett, C.R.; Matamoros, A.B.; Rolfe, S.T. Parametric Analysis of Cross-Frame Layout on Distortion-Induced Fatigue in Skewed Steel Bridges. J. Bridg. Eng. 2013, 18, 601-611. [CrossRef]

11. Sharafbayani, M.; Linzell, D.G. Optimizing Horizontally Curved, Steel Bridge, Cross-Frame Arrangements to Enhance Construction Performance. J. Bridg. Eng. 2014, 19, 04014021. [CrossRef]

12. Egilmez, O.O.; Helwig, T.A.; Herman, R. Buckling Behavior of Steel Bridge I-Girders Braced by Permanent Metal Deck Forms. J. Bridg. Eng. 2012, 17, 624-633. [CrossRef]

13. Idriss, R.L.; White, R.K. Secondary Load Paths in Bridge Systems. Ph.D. Thesis, New Mexico State University, Las Cruces, NM, USA, 1991.

14. Idriss, R.L.; White, K.R.; Woodward, C.B.; Jauregui, D.V. After-fracture redundancy of two-girder bridge: Testing I-40 bridges over Rio Grande. In Proceedings of the Fourth International Bridge Engineering Conference, San Francisco, CA, USA, 28-30 August 1995; pp. 316-326.

15. Park, Y.; Joe, W.; Park, J.; Hwang, M.; Choi, B.H. An experimental study on after-fracture redundancy of continuous span two-girder bridges. Int. J. Steel Struct. 2012, 12, 1-13. [CrossRef]

16. Connor, R.J.; Martín, F.J.B.; Varma, A.; Lai, Z.; Korkmaz, C. Fracture-Critical System Analysis for Steel Bridges; Transportation Research Board: Washington, DC, USA, 2018; ISBN 0309390540.

17. Neuman, B.J. Evaluating the Redundancy of Steel Bridges: Full-Scale Destructive Testing of a Fracture Critical Twin Box-Girder Steel Bridge. Ph.D. Thesis, University of Texas at Austin, Austin, TX, USA, 2009.

18. Irfaee, M.; Mahmoud, H. Mixed-Mode Fatigue and Fracture Assessment of a Steel Twin Box-Girder Bridge. J. Bridg. Eng. 2019, 24, 4019056. [CrossRef]

19. Hovell, C.G. Evaluation of Redundancy in Trapezoidal Box-Girder Bridges Using Finite Element Analysis. Ph.D. Thesis, University of Texas at Austin, Austin, TX, USA, 2007.

20. Samaras, V.A.; Sutton, J.P.; Williamson, E.B.; Frank, K.H. Simplified method for evaluating the redundancy of twin steel box-girder bridges. J. Bridg. Eng. 2012, 17, 470-480. [CrossRef]

21. Kim, J.; Williamson, E.B. Finite-element modeling of twin steel box-girder bridges for redundancy evaluation. J. Bridg. Eng. 2015, 20. [CrossRef]

22. Lin, W.; Yoda, T.; Kumagai, Y.; Saigyo, T. Numerical study on post-fracture redundancy of the two-girder steel-concrete composite highway bridges. Int. J. Steel Struct. 2013, 13, 671-681. [CrossRef]

23. Lin, W.; Yoda, T.; Taniguchi, N.; Lam, H.; Nakabayashi, K. Post-Fracture redundancy evaluation of a twin box-girder shinkansen bridge in Japan. In Proceedings of the IABSE Conference, Guangzhou 2016: Bridges and Structures Sustainability - Seeking Intelligent Solutions - Report; International Association for Bridge and Structural Engineering: Guangzhou, China, 2016; Volume 106, pp. 675-682.

24. Lin, W.; Lam, H.; Yoda, T. Experimental Study on Steel-Concrete Composite Twin I-Girder Bridges. J. Bridg. Eng. 2020, 25. [CrossRef]

25. Pham, H.V. Evaluation of Redundancy of Twin Steel Box-Girder Bridges. Ph.D. Thesis, Florida International University, Miami, FL, USA, 2016.

26. Conner, R.J.; Dexter, R.J.; Mahmoud, H. Inspection and Management of Bridges with Fracture-critical Details: A Synthesis of Highway Practice; Transportation Research Board: Washington, DC, USA, 2005; Volume 354, ISBN 0309097614. 
27. Abedin, M.; Maleki, S.; Kiani, N.; Shahrokhinasab, E. Shear lag effects in angles welded at both legs. Adv. Civ. Eng. 2019, 2019. [CrossRef]

28. Takahashi, S.; Tachibana, Y.; Shimura, T.; Morishita, H.; Ito, H.; Miki, C. Structural details of connection of diaphragm for rationalized plate girder bridges. Doboku Gakkai Ronbunshu 1997, 1997, 107-118. [CrossRef]

29. Kozy, B.; Tunstall, S. Stability analysis and bracing for system buckling in twin I-girder bridges. Bridg. Struct. 2007, 3, 149-163. [CrossRef]

30. Ma, H.; Shi, X. Parametric study on behaviour twin-I girder bridge systems with cross-beams. In Proceedings of the Proc. 2016 Structural Congress (Structures 2016), Seoul: Korea Federation of Science and Technology Societies, Jeju Convention Visitors' Bureau, and Korea Tourism Organization, Jeju Island, Korea, 28 August-1 September 2016.

31. AASHTO. AASHTO LRFD Bridge Design Specifications, 8th ed.; American Association of State Highway and Transportation Officials: Washington, DC, USA, 2017.

32. Kathol, S.; Azizinamini, A.; Luedke, J. Strength Capacity of Steel Girder Bridges. Final Report; Transportation Research Board: Washington, DC, USA, 1995.

33. Abedin, M.; Farhangdoust, S.; Mehrabi, A.B. Fracture detection in steel girder bridges using self-powered wireless sensors. In Proceedings of the In Risk-Based Bridge Engineering: Proceedings of the 10th New York City Bridge Conference, August 26-27, 2019; CRC Press: New York City, NY, USA, 2019; p. 216.

34. Lonetti, P.; Pascuzzo, A. Vulnerability and failure analysis of hybrid cable-stayed suspension bridges subjected to damage mechanisms. Eng. Fail. Anal. 2014, 45, 470-495. [CrossRef]

35. Lonetti, P.; Pascuzzo, A. A numerical study on the structural integrity of self-anchored cable-stayed suspension bridges. Frat. ed Integrita Strutt. 2016, 10, 359-376. [CrossRef]

36. Greco, F.; Lonetti, P.; Pascuzzo, A. A moving mesh FE methodology for vehicle-bridge interaction modeling. Mech. Adv. Mater. Struct. 2018. [CrossRef]

37. Ghaffary, A.; Karami Mohammadi, R. Framework for virtual hybrid simulation of TADAS frames using opensees and abaqus. J. Vib. Control 2018, 24, 2165-2179. [CrossRef]

38. Izadpanahi, E.; Moshtaghzadeh, M.; Radnezhad, H.R.; Mardanpour, P. Constructal approach to design of wing cross-section for better flow of stresses. In Proceedings of the AIAA Scitech 2020 Forum, Orlando, FL, USA, 6-10 January 2020; p. 275.

39. Documentation, D.A. ABAQUS/CAE Doc; Simulia: Providence, RI, USA, 2016.

40. Rahimi, E.; Shamshiripour, A.; Shabanpour, R.; Mohammadian, A.; Auld, J. Analysis of transit users' waiting tolerance in response to unplanned service disruptions. Transp. Res. Part D Transp. Environ. 2019. [CrossRef]

41. Rahimi, E.; Shamshiripour, A.; Shabanpour, R.; Mohammadian, A.; Auld, J. Analysis of Transit Users' Response Behavior in Case of Unplanned Service Disruptions. Transp. Res. Rec. 2020, 0361198120911921. [CrossRef]

42. Rahimi, E.; Shamshiripour, A.; Samimi, A.; Mohammadian, A. (Kouros) Investigating the injury severity of single-vehicle truck crashes in a developing country. Accid. Anal. Prev. 2020, 137. [CrossRef]

43. Lubliner, J.; Oliver, J.; Oller, S.; Onate, E. A plastic-damage model for concrete. Int. J. Solids Struct. 1989, 25, 299-326. [CrossRef]

44. ACI Committee 318. Building Code Requirements for Structural Concrete (ACI 318-14) and Commentary (ACI 318R-14); American Concrete Institute: Hills, MI, USA, 2014; p. 519.

45. Topkaya, C.; Williamson, E.B.; Frank, K.H. Behavior of curved steel trapezoidal box-girders during construction. Eng. Struct. 2004, 26, 721-733. [CrossRef]

46. Mouras, J.M.; Sutton, J.P.; Frank, K.H.; Williamson, E.B. The Tensile Capacity of Welded Shear Studs; Transportation Research Board: Washington, DC, USA, 2008; ISBN 9780874216561.

(C) 2020 by the authors. Licensee MDPI, Basel, Switzerland. This article is an open access article distributed under the terms and conditions of the Creative Commons Attribution (CC BY) license (http://creativecommons.org/licenses/by/4.0/). 